\title{
Cardiac Effects of Piretanide and Furosemide on Intact Anesthetized Dogs and on Isolated Atria
}

\author{
Shigetoshi Chiba, M.D., Yasuyuki Furukawa, M.D., \\ Kimiaki Saegusa, M.D., and Yasuhiro Ogiwara, M.D.
}

\section{Summary}

The effects of piretanide and furosemide on systemic arterial blood pressure and heart rate were examined in the anesthetized dog and the effects on atrial rate and contractile force were assessed in isolated atrial muscle perfused with heparinized arterial blood from a donor dog. When piretanide was administered intravenously to intact dogs, the depressor and bradycardic responses were produced dose-dependently. There were no significant simultaneous chronotropic or inotropic changes in the isolated atrium. On the other hand, furosemide $(1-3 \mathrm{mg} / \mathrm{kg})$ did not induce significant changes in either systemic blood pressure or heart rate in the intact dog. The atrial rate and developed tension were also not affected in the isolated atrium. A potent beta-adrenoceptor blocking agent, propranolol ( $1 \mathrm{mg} / \mathrm{kg}$ i.v.), consistently produced a significant depressor response and a profound negative chronotropic effect in the intact dogs; significant negative chronotropic and inotropic effects were also observed in the isolated atrium. When large doses of piretanide and furosemide were injected intraarterially into the sinus node artery of the isolated atrium, atropine-insensitive negative chronotropic and inotropic effects were induced dose-dependently. The potency of the negative chronotropic effect of piretanide was slightly greater than that of furosemide, but the negative inotropic effect of piretanide was slightly smaller than that of furosemide. These data indicate that piretanide has a depressor effect without significant cardiac influences. However, a high dose of piretanide has negative chronotropic and inotropic effects. These effects were not observed with the doses of furosemide $(1-3 \mathrm{mg} / \mathrm{kg}) \mathrm{em}$ ployed in this study.

\section{Additional Indexing Words:}

Isolated $\operatorname{dog}$ atrium Cross-perfusion method Furosemide Piretanide

TN 1969, it was reported that furosemide decreased cardiac output and 1 increased systemic vascular resistance in normovolemic subjects without cardiac or renal disease. ${ }^{11}$ In 1973, Dikshit et al $^{2)}$ reported beneficial hemodynamic effects of furosemide in congestive heart failure after myocardial

From the Department of Pharmacology, Shinshu University School of Medicine, Matsumoto 390 , Japan.

Received for publication November 25, 1986. 
infarction. Recently, it was reported that a new diuretic, piretanide Hoe 118, has the same action as furosemide at the loop of Henle ${ }^{3}$ and on the compliance of peripheral veins." Valette et al ${ }^{5 /}$ reported that the hemodynamic effects of furosemide and piretanide were quite similar. However, it was difficult to investigate direct cardiac effects, since indirect cardiac factors may modify cardiac function in situ. Thus, we used isolated and cross-perfused atrial preparations ${ }^{6 /, 7)}$ for analyzing both the direct and indirect cardiac effects of piretanide and furosemide.

\section{Methods}

Fourtcen mongrcl dogs of either sex, weighing 8 to $18 \mathrm{~kg}$, were anesthetized with sodium pentobarbital ( $30 \mathrm{mg} / \mathrm{kg}$ i.v.). Immediately after intravenous administration of sodium heparin (500 units $/ \mathrm{kg}$ ), the right atrium was excised and plunged into cold physiological saline at approximately 4 to $10^{\circ} \mathrm{C}$. The right atrium was isolated and cross-circulated with heparinized arterial blood from a donor dog according to the procedure described previously. ${ }^{6,7)}$ Briefly, the sinus node artery of the isolated atrium was cannulated at its origin in the right coronary artery. All arterial branches, except the sinus node artery, were carefully ligated. The excised right atrium was placed in a glass chamber and perfused with arterial blood from the carotid artery of the donor dog using a peristaltic pump (Harvard apparatus, model 1210). The perfusion pressure was kept constant at 100 $\mathrm{mmHg}$. The perfusion rate at this pressure was approximately $3-8 \mathrm{ml} / \mathrm{min}$ and the time delay from the donor dog to the atrium was 2 to $4 \mathrm{~min}$. The glass chamber was filled with the blood and maintained at a constant temperature of $37^{\circ} \mathrm{C}$. Bipolar platinum electrodes were placed in contact with the atrial epicardium. 'The sinus rate was measured with a tachometer triggered by atrial electrograms, and isometric tension development was measured with a force displacement transducer (Grass FTO3B). The atrial muscle was maintained under a resting tension of $2 \mathrm{gm}$. The donor dogs were respired artificially with room air by using a respirator (Harvard apparatus, model 607). The systemic blood pressure and heart rate in the donor dog and the sinus rate and tension development in the isolated atrium from another dog were recorded simultaneously on a polygraph (Nihon Kohden). Drugs used were as follows: piretanide [4-phenoxy-3-(1-pyrrolidinyl)-5sulfamoylbenzoic acid] (Hoechst A. G.), furosemide (Hoechst A. G.), dlpropranolol hydrochloride (Sumitomo Chemicals), acetylcholine chloride (Daiichi) and atropine sulfate (Takeda). The chemical structure of piretanide is shown in Fig. 1. Piretanide and furosemide were dissolved with 
$5 \mathrm{~N} \mathrm{NaOH}(\mathrm{pH} 9.8)$ and then dissolved in physiological saline.

The drug solution was either injected intravenously in a volume of 0.1-1 ml over a period of $10 \mathrm{sec}$ into the jugular vein of the donor dog, or administered in a volume of 10 to $30 \mu \mathrm{l}$ over a period of $4 \mathrm{sec}$ into the rubber tubing which conducted the blood to the arterial cannula of the isolated atrium preparation.

\section{RESULTS}

Effects of intravenous administration of piretanide to the donor dog which crosscirculated to the isolated atrium

When piretanide was intravenously administered to the donor dog, a depressor response was produced dose-dependently. However, the heart rate was not modified significantly over a dose range of $1-10 \mathrm{mg} / \mathrm{kg}$. Neither chronotropic nor inotropic effects were observed in the isolated atrium. Fig. 2(A) shows a typical response to intravenous administration of piretanide to a donor dog.

When furosemide was given intravenously ( 1 and $3 \mathrm{mg} / \mathrm{kg}$ ) to the donor dog, no significant response was observed on the systemic arterial blood pressure and heart rate. By contrast, an intravenous injection of $1 \mathrm{mg} / \mathrm{kg}$

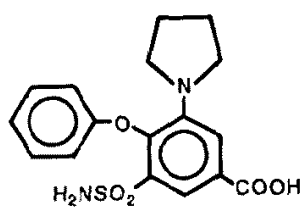

Piretanide

Fig. 1. Chemical structure of piretanide [4-phenoxy-3-(1-pyrrolidinyl)5-sulfamoylbenzoic acid].

SUPPORT DOG

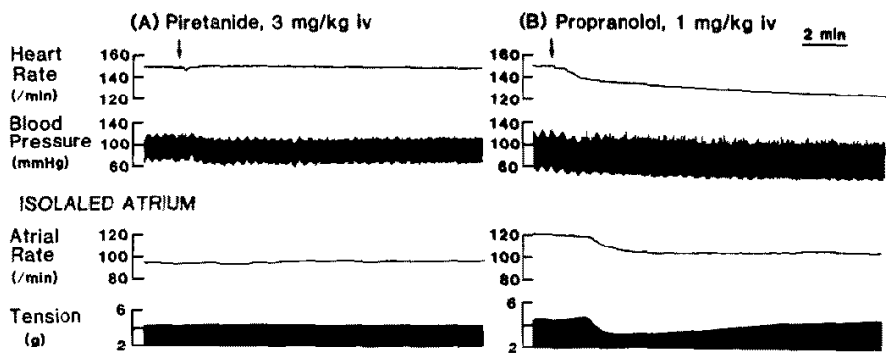

Fig. 2. Cardiovascular effects of piretanide (A) and propranolol (B) when administered into the jugular vein of a support dog. 
SUPPORT DOGS

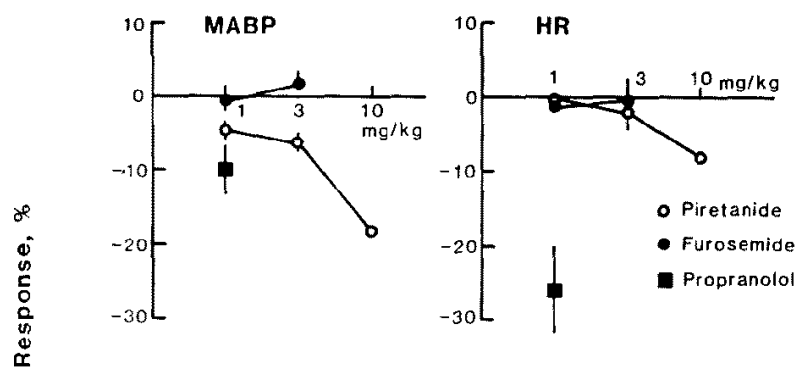

ISOLATED ATRIA
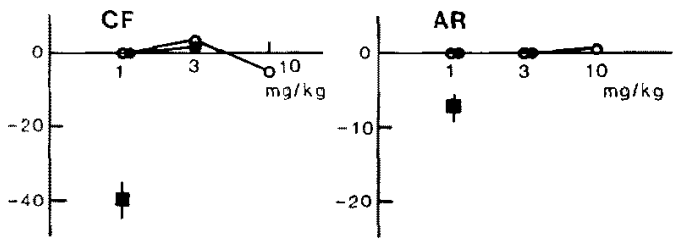

Fig. 3. Effects of piretanide, furosemide and propranolol on mean arterial blood pressure (MABP) and heart rate (HR) of donor dogs $(n=5)$, and on contractile force (CF) and atrial rate (AR) of isolated atria $(n=5)$. Control MABP was $106 \pm 4.6 \mathrm{mmHg}$ (mean $\pm \mathrm{SEM}$ ) and control $\mathrm{HR}$ was $158 \pm$ 13.0 beats/min in support dogs. The control atrial rate was $102 \pm 5.6$ beats/ min and the control contractile force was $3.9 \pm 0.6 \mathrm{gm}$ in isolated atria $(n=5)$.

of propranolol induced a marked depressor response with profound bradycardia in the donor dog and negative chronotropic and inotropic responses in the isolated atrium. Fig. 2(B) shows a record during intravenous administration of $1 \mathrm{mg} / \mathrm{kg}$ of propranolol to a donor dog. Data are summarized in Fig. 3.

Effects of intraarterial injection of piretanide into the sinus node artery of the isolated atrium

When piretanide was injected into the cannulated sinus node artery of the isolated atrium, slight dose-dependent negative chronotropic and inotropic effects were induced. The threshold dose for inducing significant responses was approximately $1 \mathrm{mg}$. The solvent induced a positive inotropic effect without changes in atrial rate. Furosemide also induced slight negative chronotropic and inotropic responses in isolated atria. Data are summarized in Fig. 4.

The piretanide-induced negative chronotropic and inotropic effects were not modified by atropine $(3-10 \mu \mathrm{g})$ in doses which completely inhibited acetylcholine $(0.3 \mu \mathrm{g})$-induced negative chronotropic and inotropic effects in 2 experiments. Fig. 5 shows records of the effects of $3 \mu \mathrm{g}$ of atropine on 

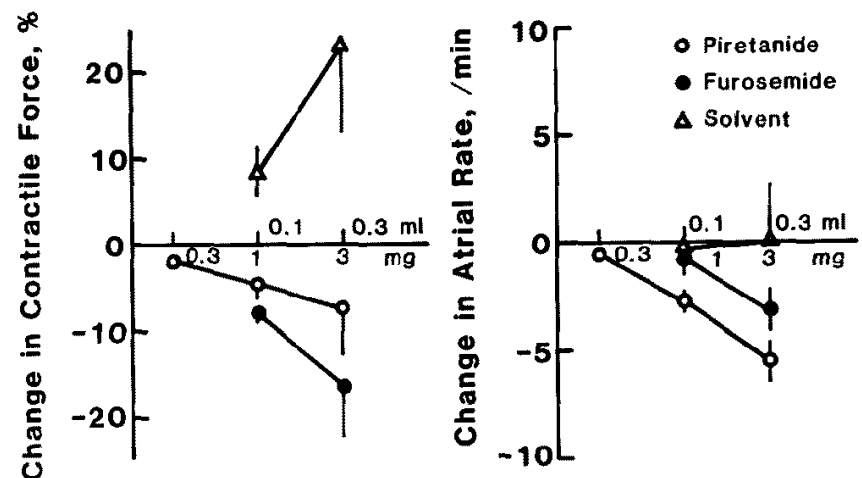

Fig. 4. Inotropic and chronotropic effects of piretanide, furosemide and solvent when given selectively into the cannulated sinus node artery of the isolated atrium $(n=5)$.

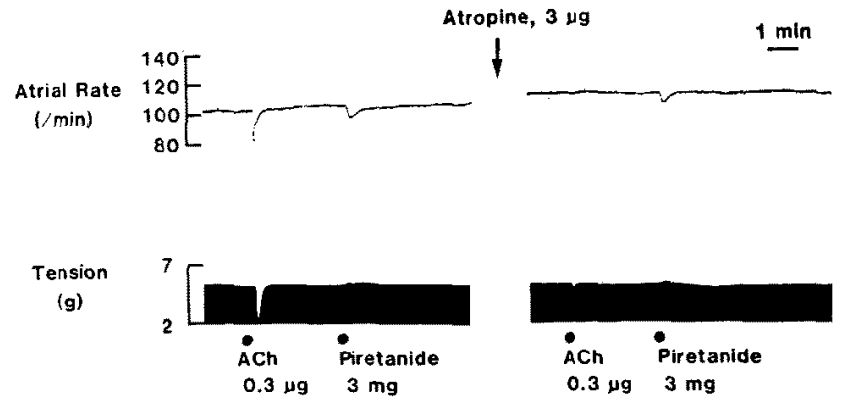

Fig. 5. Effects of $3 \mu \mathrm{g}$ of atropine on responses to $0.3 \mu \mathrm{g}$ of acetylcholine (ACh) and $3 \mathrm{mg}$ of piretanide in an isolated dog atrium.

acetylcholine- and piretanide-induced cardiac responses.

\section{Discussion}

It has been reported that piretanide is a potent 'loop' diuretic, with a principal site of action in the thick ascending limb of the loop of Henle. ${ }^{8)-10}$ ) Furosemide has been found to increase venous capacitance ${ }^{11}$ and to relieve pulmonary edema. ${ }^{12)}$ The loop diuretics are effective for the treatment of cdema of cardiac origin. ${ }^{1), 2), 8}$ It is considered that successful diurctic therapy should serve to increase cardiac output by reducing systemic vascular resistance. However, the direct cardiac effects of these diuretics have not been adequately characterized.

In the present study, we used cross-circulated dog atrial preparations to observe simultaneously the direct and indirect cardiac effects of the test drug. We previously investigated the chronotropic and inotropic effects of several 

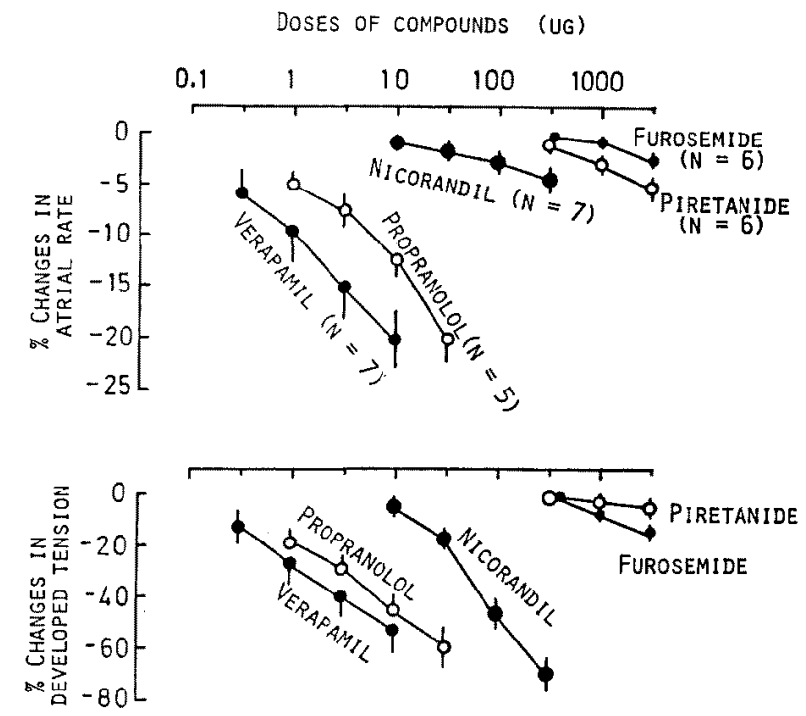

Fig. 6. Dose-response curves for the chronotropic and inotropic responses to verapamil, propranolol, nicorandil, furosemide and piretanide. A continuous line indicates the maximum negative chronotropic and inotropic responses. T'hese results were obtained from 4-10 experiments. Vertical lines represent SEM.

cardioactive substances in isolated and blood-perfused dog atrial preparations. ${ }^{13)-15)}$ Thus, we can compare the actions of other cardioactive substances with piretanide and furosemide (Fig. 6). It is clear that two potent loop diuretics, piretanide and furosemide, have no significant direct cardiac effects over a relatively large dose range. An extremely large dose of piretanide or furosemide has slight negative chronotropic and inotropic properties. The piretanide-induced negative chronotropic and inotropic effects were not mediated via cholinergic mechanisms, since they were not inhibited by atropine. These data indicate that therapeutic doses of piretanide have no direct cardiac action, but that extremely large doses of piretanide have a cardiac depressant property. Furthermore, they imply that beneficial cardiac effects of piretanide may be due to secondary effects of either its potent diuretic actions or other extra-cardiac factors, such as hypotension.

\section{RefERENCES}

1. Lal S, Murtagh JG, Pollock AM, Flecher E, Binnion PF: Acute hemodynamic effects of furosemide in patients with normal and raised left atrial pressure. Br Heart J 31: 711, 1969

2. Dikshit K, Vyden JK, Forrester JS, Chatterjee K, Prakash R, Swan HJ: Renal and extra renal hemodynamic effects of furosemide in congestive heart failure after myocardial infarction. New Engl J Med 288: 1087, 1973 
3. Merkel W, Bormann D, Mania D, Muschawek R, Hropot M: Piretanide (HOE 118), a new high ceiling salidiuretic. Eur J Med Chem Ther 5: 309, 1976

4. Valette $\mathbf{H}$, Duhage $\mathbf{P}$, Apoil $\mathbf{E}$ : Plethysmographic study with furosemide and piretanide in healthy volunteers. Br J Clin Pharmacol 7: 219, 1979

5. Valette H, Herbert J-L, Raffestin B, Lockhart A, Apoil E: Comparison of hemodynamic effects of furosemide and piretanide in normovolemic patients. J Gardiovasc Pharmacol 2: 103,1980

6. Chiba S, Kimura T, Hashimoto K: Muscarinic suppression of the nicotinic action of acetylcholine on isolated, blood-perfused atrium of the dog. Naunyn-Schniedeb Arch Pharmacol 289: 315,1975

7. Chiba S, Yabuuchi $\mathrm{Y}$, Hashimoto $\mathrm{K}$ : Comparison of the effects of norepinephrine and acetylcholine between intraarterial and extravascular administration to the isolated, bloodperfused canine atrium. Jpn J Pharmacol 25: 433, 1975

8. Clissold SP, Brogden RN: Piretanide. A preliminary review of its pharmacodynamic and pharmacokinetic properties, and therapeutic efficacy. Drugs 29: 489, 1985

9. Tredesai P, Puschett JB: Acute effects of piretanide in normal subjects. Clin Pharmacol Therap 25: 331, 1979

10. McNabb WR, Noormohamed FH, Brooks BA, Lant AF: Renal actions of piretanide and three other ' loop' diuretics. Glin Pharmacol Therap 35: 328, 1984

11. Johnston GD, Nicholls DP, Leahey WJ, Finch MB: The effects of captopril on the acute vascular responses to frusemide in man. Clin Sci 65:359, 1983

12. Bhatia PK, Singh I, Manchanda SC, Khanna PK, Row SB: Effect of frusemide on pulmonary blood volume. Br Med J 2: 551, 1969

13. Chiba S: Effects of verapamil on the blood-perfused, isolated atrium preparation of the dog heart. Jpn Heart J 16: 709, 1975

14. Chiba S, Kobayashi M, Furukawa Y: Effects of disopyramide on SA nodal pacemaker activity and contractility in the isolated blood-perfused atrium of the dog. Eur J Pharmacol 57: 13,1979

15. Chiba S, Furukawa Y, Kobayashi M: Differential chronotropic and inotropic effects of 2-nicotinamidoethylnitrate (SG-75) in the dog isolated atrium. Clin Exp Pharmacol Physiol 7: 205,1980 